\title{
The Isopiestic Method: 100 Years Later and Still in Use
}

\author{
Joseph A. Rard ${ }^{1}$ \\ Published online: 12 March 2019 \\ (c) Springer Science+Business Media, LLC, part of Springer Nature 2019
}

\section{The Historical Development of the Isopiestic Method and Its Applications to Aqueous Systems}

Bousfield first described the isopiestic method on 12 December 1917 at a meeting of the Faraday Society and his results were subsequently published in the Transactions of the Faraday Society [1]. In its initial application, Bousfield studied the water vapor pressures required to begin hydrating and then dissolving initially dry samples of $\mathrm{NaCl}, \mathrm{KCl}$, and $\mathrm{KNO}_{3}$, thus yielding the vapor pressure and consequently the water activities of their saturated solutions at $291 \mathrm{~K}$. Solutions of $\mathrm{LiCl}(\mathrm{aq})$ were also present during the experiments and were used as standard solutions for determining the vapor pressure of water. Bousfield's apparatus consisted of a Hempel desiccator containing a tin stand with four glass dishes to hold the salt samples. The total amount of water in the system was controlled by adding a little water or desiccant to the desiccator's lid at the start of an experiment.

Sinclair [2] recognized the potential of the isopiestic method for determining accurate water vapor pressures of unsaturated aqueous solutions, provided that stirring of the solutions occurred and the solutions were put into good thermal contact to ensure that the temperature was highly uniform among them while being simultaneously equilibrated in the desiccator. Sinclair replaced Bousfield's glass dishes with silver-plated copper dishes to hold the solution samples and placed them together on a $2.5 \mathrm{~cm}$ thick silver-plated copper block to provide good thermal conductivity, removed most of the air from the desiccator using a water aspirator, and rocked the desiccator back and forth inside a constant temperature bath to mix the solutions and thus eliminate the concentration gradients that built up as water was exchanged among solutions through their common vapor space. These changes led to a major improvement in the precision and accuracy of the experimental results and reduction of the time necessary to achieve thermodynamic equilibrium. However, no individual caps were provided to cover the dishes when they were removed from the desiccator for weighing and, as noted by Sinclair, solvent losses of up to several milligrams may have occurred before the final weighings. This was the most significant remaining source of experimental error because the masses of the solutions are needed for

This review is dedicated to the maestro of high-temperature isopiestic measurements, Dr. Howard F. Holmes, who died 22 March 2013 at age 81.

Joseph A. Rard

solution_chemistry2@comcast.net

Livermore, CA, USA 
calculating the molalities of the solutions when they reach isopiestic equilibrium. Sinclair also noted that the thick walls of the desiccator acted to smooth out minor variations in the temperature of the thermostat, producing a more uniform temperature inside the desiccator. Although not stated, the relatively low thermal conductivity of the glass desiccator is a distinct advantage in the thermal buffering of the interior of the desiccator. The following year Robinson and Sinclair [3] replaced the silver-plated copper dishes with silver dishes, gold plated on the inside to make them corrosion resistant, with hinged-flap lids that could be closed before the sample dishes were removed from the desiccator for weighing. With these changes and then replacing the flap lids with tight fitting caps [4], the isopiestic equilibrium method became a quantitative method for the determination of water activities of aqueous solutions.

Numerous variations have been reported on the design of an isopiestic apparatus and the containers used to hold the solution samples, mostly minor, as described in detail in the review of this method in the second edition of Activity Coefficients in Aqueous Solutions [4]. As indicated in that review, most isopiestic apparatuses for use below about $373 \mathrm{~K}$ have been constructed from modified vacuum glass desiccators or chambers constructed from a metal, typically stainless steel $[5,6]$. However, plastic desiccators such as those constructed of Lucite [7, 8] have also been used. Nearly all types of isopiestic apparatus contain a thick copper block (frequently gold plated) because it provides a very efficient heat transfer medium to eliminate initial temperatures differences among the solution samples and those that arise from evaporation (endothermic) or condensation (exothermic) of solvent from the solution samples as they approach isopiestic equilibrium. Aluminum heattransfer blocks have also been used [4].

Good thermal conductivity of the sample vessels containing the solutions is obviously also very important, but resistance to corrosion by the solutions is the determining factor in determining whether a particular solid material can be used. These vessels are usually called dishes or cups, depending on their shape. Silver metal has frequently been used for these vessels but it is not inert to some electrolyte solutions. For example, Robinson [9] found that aqueous solutions of the alkali metal iodides readily corroded silver metal dishes while Lindenbaum and Boyd [10] similarly found that some tetraalkyl ammonium halides also caused severe corrosion (both chlorides and bromides were studied but they did not specify which of their salts caused the corrosion). Silver vessels for the solutions are commonly gold plated on the inside to reduce the likelihood of corrosion but this coating must be completely free of imperfections. Popović et al. [11], for example, found that aqueous mixtures of $\mathrm{KBr}$ and $\mathrm{K}_{2} \mathrm{HPO}_{4}$ were able to corrode the gold-plated silver dishes, apparently through "pinholes" in the gold layer, as evidenced by a golden-colored turbidity (presumably from silver bromide) in the solutions at the end of the isopiestic equilibrations.

Other, more corrosion resistant metals have been used as solution containers for isopiestic experiments. For example, platinum has been used for holding $\mathrm{H}_{2} \mathrm{SO}_{4}(\mathrm{aq})[5,12,13]$, $\mathrm{CH}_{3} \mathrm{SO}_{3} \mathrm{H}(\mathrm{aq})$ [14] and other corrosive solutions [15, 16], as have titanium dishes [17] including those for the high-temperature isopiestic unit at Oak Ridge National Laboratory [18]. The sample cups for this author's research [19-21] are made of tantalum metal, which is very corrosion resistant including to concentrated solutions of sulfuric acid as long as its surface is covered by an intact thin protective surface layer of $\mathrm{Ta}_{2} \mathrm{O}_{5}$. Although resistant to most acids and most other solutions, tantalum can be corroded by HF and concentrated hydroxide solutions. However, the thermal conductivities of these three metals are significantly lower than that of silver by a factor of 0.17 for $\mathrm{Pt}, 0.051$ for $\mathrm{Ti}$ and 0.13 for Ta around room temperature, see Table 9 of Rard and Platford's review article [4], so it will take longer for the temperatures of solutions in dishes or cups of these metals to equalize. As also pointed out in section V. A. 
of that review, when gold-plated silver cups were replaced with cups of tantalum metal then the times required to reach isopiestic equilibrium at higher molalities were little affected but for low molalities the experiments took several times longer than for silver because of the lower rate of heat transfer. A similar situation should occur for dishes and cups made of platinum, titanium and other corrosion resistant metals.

It is generally found that the time to reach isopiestic equilibrium for a specific apparatus with sample dishes or cups made of the same metal varies little with the molality of the solution at intermediate and high molalities, whereas longer equilibration times are needed at low molalities, e.g. references $[2,3,5,6,19]$, where larger amounts of water may need to be exchanged among the solutions being equilibrated and differences in the Gibbs energy of water among them (the driving force for isopiestic equilibration) are much smaller. A comparison of the driving force values for various molalities of $\mathrm{NaCl}(\mathrm{aq}), \mathrm{CaCl}_{2}(\mathrm{aq})$ and $\mathrm{H}_{2} \mathrm{SO}_{4}(\mathrm{aq})$ at $T=298.15 \mathrm{~K}$ is given by Rard and Platford in their Table 8 [4]; these values decrease by factors of $\sim 100$ to $\sim 300$ when decreasing the molalities from $6.0 \mathrm{~mol} \cdot \mathrm{kg}^{-1}$ to $0.1 \mathrm{~mol} \cdot \mathrm{kg}^{-1}$, and by a factor of $\sim 1000$ for $\mathrm{H}_{2} \mathrm{SO}_{4}(\mathrm{aq})$ in going from $25.0 \mathrm{~mol} \cdot \mathrm{kg}^{-1}$ to $0.1 \mathrm{~mol} \cdot \mathrm{kg}^{-1}$. The lack of significant variation in the time required to reach isopiestic equilibrium at intermediate and high molalities of solutions suggests that heat transport and the resulting time required for precise equalization of temperature is the main factor governing the rate at which isopiestic equilibrium is reached at these concentrations. But, at low concentrations where the time to reach equilibrium becomes significantly longer, the kinetics become mass transport limited because of the much smaller differences in the Gibbs energies of water among the solutions and the larger masses of water that need to be exchanged [4]; a similar conclusion was reached earlier by Gordon [22] that the kinetics become mass transport limited for dilute solutions of $\mathrm{NaCl}(\mathrm{aq})$ and $\mathrm{KCl}(\mathrm{aq})$ at molalities $\leq 0.1 \mathrm{~mol} \cdot \mathrm{kg}^{-1}$. The argument for heat transport being the dominant factor controlling the time needed to reach isopiestic equilibrium over most of the concentration range is supported by the observation that when the silver metal dishes or cups are replaced with ones of glass or another metal with lower thermal conductivity then the times needed to reach isopiestic equilibrium increase. Also, as pointed out by Platford [23], the times necessary to reach isopiestic equilibrium in his apparatus at $T=273.15 \mathrm{~K}$ "are not noticeably greater" than at $T=298.15 \mathrm{~K}$, which is also consistent with a heat transport limiting process rather than a mass transport limiting process.

The effect of a temperature difference on isopiestic measurements can be described by using the following extension of the approach given by Rard and Platford [4, their Eqs. 33-41]. The molality-based or "practical" osmotic coefficient $\phi$ is nearly always used for analyzing the water activities of aqueous solutions because it provides a much more sensitive measure of deviations from ideal behavior at low molalities that is needed when deriving mean activity coefficients of solutes from isopiestic data. This osmotic coefficient of an aqueous solution is defined as

$$
\ln a_{\mathrm{w}}=-M_{\mathrm{w}} \phi \sum_{i} v_{i} m_{i}
$$

where $a_{\mathrm{w}}$ is the activity of water, $M_{\mathrm{w}}=0.0180153 \mathrm{~kg} \cdot \mathrm{mol}^{-1}$ is the molar mass of water, $m_{i}$ is the molality of electrolyte $i$ in the solution, and $\nu_{i}$ is the stoichiometric ionization number of this electrolyte (the same equation applies to non-electrolyte solutions where $\nu=1$ ). The water activity is defined as

$$
a_{\mathrm{w}}=f_{\mathrm{w}} / f_{\mathrm{w}}^{\mathrm{o}}
$$


where $f_{\mathrm{w}}$ is the fugacity of water vapor for the solution and $f_{\mathrm{w}}^{\mathrm{o}}$ the corresponding fugacity for pure water at the same temperature. Let two solutions of the same electrolyte or mixtures of electrolytes with the same solute ratio be at isopiestic equilibrium but also be at different temperatures $T_{1}$ and $T_{2}$. Because they are in isopiestic equilibrium through a common vapor phase they will have the same vapor pressure of water and thus the same water fugacity, $f_{\mathrm{w}}\left(T_{1}\right)=f_{\mathrm{w}}\left(T_{2}\right)$. However, the water activities will be different because the vapor pressures and thus the fugacities of pure water at these two temperatures are different, $f_{\mathrm{w}}^{\mathrm{o}}\left(T_{1}\right) \neq f_{\mathrm{w}}^{\mathrm{o}}\left(T_{2}\right)$. Then,

$$
\ln a_{\mathrm{w}}\left(T_{1}\right)-\ln a_{\mathrm{w}}\left(T_{2}\right)=\ln \left\{a_{\mathrm{w}}\left(T_{1}\right) / a_{\mathrm{w}}\left(T_{2}\right)\right\}=\ln \left\{f_{\mathrm{w}}^{\mathrm{o}}\left(T_{2}\right) / f_{\mathrm{w}}^{\mathrm{o}}\left(T_{1}\right)\right\}
$$

Combining this equation with Eq. 1 then yields

$$
\left(1 / M_{\mathrm{w}}\right) \ln \left\{f_{\mathrm{w}}^{\mathrm{o}}\left(T_{2}\right) / f_{\mathrm{w}}^{\mathrm{o}}\left(T_{1}\right)\right\}=\phi\left(T_{2}\right) \sum_{i} v_{i} m_{i}\left(T_{2}\right)-\phi\left(T_{2}\right) \sum_{i} v_{i} m_{i}\left(T_{1}\right)
$$

This equation is exact for a bithermal isopiestic experiment, i.e., when the two samples are deliberately kept at different temperatures but are still equilibrated through a common vapor phase. One of the few cases where this bithermal isopiestic method has been used to study aqueous solutions was the study by Glueckauf and Kitt [24] of very concentrated solutions of $\mathrm{H}_{2} \mathrm{SO}_{4}(\mathrm{aq}), \sim 20$ to $\sim 65 \mathrm{~mol} \cdot \mathrm{kg}^{-1}$, where solutions of lower molality held at $T=273.5_{5} \mathrm{~K}$ were used as standards for higher molality solutions held at $T=298.1_{5} \mathrm{~K}$.

The term on the left-hand-side of Eq. 4 distinguishes it from the usual relation for solutions in isopiestic equilibrium when no temperature difference is present. For a typical isopiestic experiment with the desiccator or chamber equilibrated in a liquid-filled thermostat, the temperature inside the apparatus at isopiestic equilibrium will be highly uniform and thus the term on the left-hand-side of Eq. 4 will be essentially zero. However, the hightemperature isopiestic unit at Oak Ridge National Laboratory (ORNL) that was designed for operation at $T \sim 383 \mathrm{~K}$ to over $500 \mathrm{~K}$ is fundamentally different in design than isopiestic apparatuses designed for operation at lower temperatures. Because of likely issues with significant solvent loss if solution samples equilibrated at high temperatures were to be removed for weighing at room temperature, the sample dishes and their solutions are instead weighed inside the isopiestic unit at the actual experimental temperature using a self-contained electromagnetic balance. Photographs of this isopiestic apparatus and the electromagnetic balance are given in Ref. [4]. Because of potential hazards from the use of a liquid filled thermostat at such high temperatures, an air-bath thermostat is used instead. However, because it is more difficult to precisely control the temperature of an air-bath thermostat, there was a persistent temperature difference of about $0.02 \mathrm{~K}$ present across the copper heat transfer block which led to differences of about $2 \%$ between molalities of pairs of solutions of the same electrolyte located on opposite sides of the block for solutions of lower molalities [18], but subsequent modifications reduced this temperature difference to about $0.01 \mathrm{~K}$ [25]. The size of the effect of this temperature difference will be calculated for $\Delta T=0.01 \mathrm{~K}$ at $T=373.15 \mathrm{~K}$ using the critically-assessed vapor pressures of water reported by Wexler and Greenspan [26]:

$$
\left(1 / M_{\mathrm{w}}\right)=\ln \left\{f_{\mathrm{w}}^{\mathrm{o}}(373.14 \mathrm{~K}) / f_{\mathrm{w}}^{\mathrm{o}}(373.15 \mathrm{~K})\right\}=-0.020 \mathrm{~mol} \cdot \mathrm{kg}^{-1}
$$

and, similarly, at $T=298.15 \mathrm{~K}$ :

$$
\left(1 / M_{\mathrm{w}}\right)=\ln \left\{f_{\mathrm{w}}^{\mathrm{o}}(298.14 \mathrm{~K}) / f_{\mathrm{w}}^{\mathrm{o}}(298.15 \mathrm{~K})\right\}=-0.033 \mathrm{~mol} \cdot \mathrm{kg}^{-1} .
$$

It is thus clear that the presence of a temperature gradient of fixed size, if present, would give rise a larger error in the measured molality and osmotic coefficient $\phi$ at lower 
temperatures than at higher ones and, by Eq. 4, the corresponding error decreases with increasing molality of the solution. This is in agreement with the observations of Holmes et al. $[18,25]$ that molalities of replicate samples were in good agreement at higher molalities but not at lower molalities.

For isopiestic experiments around room temperature it is possible to rapidly cap the sample dishes or cups after the apparatus is opened so there is little solvent loss before the samples are weighed and thus the calculated molalities should be reliable. However, if the temperature of the isopiestic experiment is much lower or much higher than room temperature then condensation of atmospheric moisture or significant evaporation of solvent from the samples could occur when they are removed from the isopiestic apparatus and to prevent this it is essential that the dishes or cups be capped while still inside the apparatus and still at the experimental temperature. See, for example, the studies of Rush and Johnson [7], Humphries et al. [27], Grjotheim et al. [28] and Hefter et al. [29]. Rard and Platford [4] estimated the mass error for samples capped at $T=273.15 \mathrm{~K}$ and $T=298.15 \mathrm{~K}$ and then weighed at $T=298.15 \mathrm{~K}$ as being $\sim 1 \times 10^{-4} \mathrm{~g}$ and $\sim 1 \times 10^{-4} \mathrm{~g}$, respectively, when $a_{\mathrm{w}}=0.9$ for an isopiestic dish or cup of typical size, which is an essentially negligible contribution to the experimental error. However, at $T=373.15 \mathrm{~K}$ the mass of excess water is about 80 times larger, which would be a significant source of error if the molalities are not corrected for this excess water. Hefter et al. [29] have analyzed this situation in detail and have provided equations for calculating the correct molalities of solutions at isopiestic equilibrium.

The isopiestic method owes its simplicity to the fact that its basic measurement is a mass measurement and normally the solutions contain only one volatile component, the "solvent". The solute or solutes can be added either as aliquots of a carefully standardized solution of known molality or as samples of the corresponding anhydrous solid or solids. Then, as long as the solutes are not volatile and are hydrolytically stable, the number of moles of the solute or solutes is both known and remains unchanged during the isopiestic equilibrations. Any mass change of solutions during the isopiestic equilibration is therefore due solely to solvent gain or loss, and by weighing the isopiestic dish or cup with its solution, the mass of water and thus the molality of the solute or solutes in the equilibrated solution can be calculated. Under these conditions multiple sequential equilibrations can be made using the same solute samples. Liquids of very low volatility can also be studied in the presence of water, e.g. the water + glycerol system was studied by Scatchard et al. [5] at $T=298.15 \mathrm{~K}$ where the glycerol is considered as a solute.

In most isopiestic experiments nearly all of the air is removed from the apparatus because the mean free path of water molecules and of other gaseous molecules depends inversely on the pressure, and consequently water molecules can be exchanged more rapidly among solution samples by way of their common vapor phase. Scatchard et al. [5] described a method to evacuate most of the air an isopiestic apparatus that avoids the too rapid removal of air that could lead to boiling and spattering of the solution if a vacuum pump is used. First, a vessel of similar size is evacuated using a vacuum pump, this vessel in then connected to the isopiestic apparatus, resulting in a reduction of the vapor pressure to half of its original value. The isopiestic apparatus is then isolated from the ballast vessel, which is re-evacuated by the vacuum pump, and the process repeated for several cycles until the vapor pressure inside the isopiestic apparatus has decreased to the desired level. Removal of most of the air is more important for solutions of low molality but need not be as complete for solutions of higher concentration [4].

In contrast, Kirgintsev and Luk'yanov [30] and subsequently Michimoto et al. [31] described the use of an isopiestic apparatus in which the air was not removed and a 
propeller was used to stir the vapor phase. However, the apparatus lacks a heat-transfer block and the liquid solutions were contained in glass cuvettes of low thermal conductivity, and there was a continuous source of heat input at the top of the apparatus from the electrical motor controlling the propeller, so this method is unlikely to yield as accurate results as those using isopiestic apparatuses of more traditional design. Mitchell et al. [32] in Albright's laboratory described the addition of a fan-like object to stir the water vapor in an isopiestic desiccator with air removed; the device was a metal fan with one blade removed to make it off center and its vapor stirring motion was the result of rotation of the desiccator to keep the solutions mixed as they were equilibrated. Since no electrical motor was used to provide the vapor stirring, no additional (undesirable) heat source was present. Rard subsequently adopted a modified version of this water-vapor stirring fan-like device for his isopiestic chambers [33].

Rard and Platford [4] list a few aqueous systems where the solutes were found to be too volatile under isopiestic conditions to yield meaningful results $\left\{\left(\mathrm{CH}_{3}\right)_{3} \mathrm{~N} \cdot \mathrm{HCl}, \mathrm{H}_{3} \mathrm{BO}_{3}\right.$, and possibly $\mathrm{NaBF}_{4}$ at $T=298.15 \mathrm{~K}$ \} or underwent hydrolysis (in some cases with loss of $\mathrm{HCl}$ through the vapor phase) $\left\{\mathrm{UO}_{2} \mathrm{Cl}_{2}, \mathrm{NaBF}_{4}, \mathrm{Na}_{2} \mathrm{H}_{2} \mathrm{P}_{2} \mathrm{O}_{7}\right.$ and $\mathrm{K}_{2} \mathrm{H}_{2} \mathrm{P}_{2} \mathrm{O}_{7}$ at $T=298.15 \mathrm{~K}$; $\mathrm{CoCl}_{2}$ at $T=413.36 \mathrm{~K}$ \}. Subsequently, Holmes and Mesmer [34] found that $\mathrm{H}_{2} \mathrm{SO}_{4}(\mathrm{aq})$ lost some of this solute, presumably as $\mathrm{SO}_{3}(\mathrm{~g})$, during isopiestic experiments at $T \sim 498$ and $\sim 523 \mathrm{~K}$ as evidenced by hysteresis in the results and confirmed by acid/base titration at the end of the experiments, but no such problem was encountered at $T \leq 473.21 \mathrm{~K}$. Isopiestic measurements for $\mathrm{Cu}\left(\mathrm{NO}_{3}\right)_{2}(\mathrm{aq})$ at $T=298.15 \mathrm{~K}$ [35] showed strong hysteresis at high molalities due to loss of $\mathrm{HNO}_{3}$ during the equilibrations, but the effect was negligible or comparable to the experimental uncertainty below $\sim 3.8 \mathrm{~mol} \cdot \mathrm{kg}^{-1}$. Rard [36] similarly found that $\mathrm{CuCl}_{2}(\mathrm{aq})$ lost $\mathrm{HCl}$ during isopiestic equilibrations at $T=298.15 \mathrm{~K}$, as evidenced both by hysteresis of the results and slight corrosion of the lid of the stainless isopiestic chamber right above the cups that held the $\mathrm{CuCl}_{2}(\mathrm{aq})$ solutions. There are relatively few electrolyte systems that exhibit such volatility or hydrolytic instability under isopiestic conditions, and hundreds of binary, ternary and higher-order aqueous systems have been successfully studied by the isopiestic method. References to many of these studies can be found in the reviews by Rard and Platford [4] and by Pitzer [37].

\section{Standards (Reference Solutions) for Aqueous Systems}

The above description of the isopiestic method indicates that it is a relative method where some of the solutions must be (standard) reference solutions whose osmotic coefficients have been well characterized as functions of molality. The fundamental equation for isopiestic equilibration is:

$$
\phi=v_{\mathrm{R}} m_{\mathrm{R}} \phi_{\mathrm{R}} / \sum_{i} v_{i} m_{i}
$$

where the subscript $\mathrm{R}$ denotes a reference solution in isopiestic equilibrium with the investigated solution and $\phi$ is the sought after molality-based osmotic coefficient of the investigated solution. The most commonly used aqueous reference solutions for isopiestic experiments are $\mathrm{NaCl}(\mathrm{aq}), \mathrm{KCl}(\mathrm{aq}), \mathrm{CaCl}_{2}(\mathrm{aq})$, and $\mathrm{H}_{2} \mathrm{SO}_{4}(\mathrm{aq})$. The best current critical evaluations for $\mathrm{NaCl}(\mathrm{aq})$ and $\mathrm{KCl}(\mathrm{aq})$ are those of Archer [38, 39], where the evaluations are based on thermodynamic data from water freezing temperatures to about $600 \mathrm{~K}$ 
for $\mathrm{NaCl}(\mathrm{aq})$ and to about $420 \mathrm{~K}$ for $\mathrm{KCl}(\mathrm{aq})$. However, because of solubility limitations, the model for $\mathrm{NaCl}(\mathrm{aq})$ is limited to water activities of $>0.76$, but with an even narrower water activity range for $\mathrm{KCl}(\mathrm{aq})$. The critical review of Clegg et al. [40] for $\mathrm{H}_{2} \mathrm{SO}_{4}(\mathrm{aq})$ provides a comprehensive evaluation of its osmotic coefficients for $m \leq 6 \mathrm{~mol} \cdot \mathrm{kg}^{-1}$ and $273.15 \leq T / \mathrm{K} \leq 328.15$, which corresponds to water activities of approximately $\geq 0.626$ at $T=298.15 \mathrm{~K}$. Probably the best critical evaluation of the osmotic coefficients of $\mathrm{H}_{2} \mathrm{SO}_{4}(\mathrm{aq})$ at higher molalities is that of Rard et al. [41] at $T=298.15 \mathrm{~K}$ for $m \leq 27.0 \mathrm{~mol} \cdot \mathrm{kg}^{-1}$, corresponding to $a_{\mathrm{w}} \geq 0.029$, and whose values of $\phi$ connect up well with those from the Clegg et al. evaluation [40] at $6 \mathrm{~mol} \cdot \mathrm{kg}^{-1}$. Although evaluations are available for $\mathrm{H}_{2} \mathrm{SO}_{4}(\mathrm{aq})$ at other temperatures, the available data needed to characterize the osmotic coefficients are much less extensive than at $T=298.15 \mathrm{~K}$ and frequently less precise. The Rard and Clegg [42] critical evaluation for $\mathrm{CaCl}_{2}(\mathrm{aq})$ at $T=298.15 \mathrm{~K}$ yields results for the molality range $m \leq 10.77 \mathrm{~mol} \cdot \mathrm{kg}^{-1}$ and $a_{\mathrm{w}} \geq 0.16$.

As described by Rard and Platford [4], some authors have used other electrolyte solutions as standards, most frequently $\mathrm{LiCl}(\mathrm{aq})$. The osmotic coefficients of these other provisional standards are usually not as well characterized as the above four electrolytes and their use is not generally recommended, but the reason for their use for measurements at low water activities is understandable when the solution containers may not be sufficiently corrosion resistant for use with $\mathrm{H}_{2} \mathrm{SO}_{4}(\mathrm{aq})$.

\section{Solubility Determinations by Isopiestic Measurements}

The isopiestic method can also be used to simultaneously measure the water activity and solubility of saturated solutions, where a reservoir of saturated solution with crystals is equilibrated with solutions not containing the solid phase; this method has been reviewed for single solute systems [43]. Fillipov et al. in Russia have made extensive measurements of this type for mixed salt systems and references to many of these studies are given in Pitzer's review article [37].

\section{Isopiestic Measurements for Non-aqueous Systems}

Although the above description of the isopiestic method has emphasized its most frequent applications to determining the water activities and osmotic coefficients of aqueous solutions, there is nothing inherent in the method that limits it to aqueous solutions. In principle, any solution in a liquid solvent may be studied by the isopiestic method provided that there is some solution in that solvent whose osmotic coefficients are sufficiently well characterized that it can serve as an isopiestic standard. Unfortunately, there are relatively few systems with the necessary standard data but Rard and Platford [4] have cited isopiestic studies in $\mathrm{D}_{2} \mathrm{O}$, methanol, and benzene. The calculations for $\mathrm{D}_{2} \mathrm{O}$ solutions required the approximation that osmotic coefficients of $\mathrm{KCl}$ in $\mathrm{D}_{2} \mathrm{O}$ are the same as in $\mathrm{H}_{2} \mathrm{O}$ at equal aquamolalities since there was no adequate standard at that time for $\mathrm{D}_{2} \mathrm{O}$ solutions. In the nonaqueous systems the solutions used as standards were $\mathrm{NaI}$ in methanol and benzyl in benzene.

Since that review [4], Wang et al. [44, 45] have reported additional isopiestic results for methanol and ethanol solutions. Zafarani-Moattar and Jahanbin-Sardroodi [46, 47] have reported isopiestic data for several electrolytes in ethanol as have Zafarani-Moattar and 
Aria [48] for several electrolytes in 2-propanol. These last three studies [46-48] used the so-called "improved isopiestic method" [49] in which solutions are contained in a glass manifold where there is no heat-transfer medium. If the solutions are not stirred, then homogenization of the solutions occurs only by liquid state diffusion. The method used to determine the molalities (or masses of solutions without significant solvent vapor loss) was not described [46-48]. The so-called improved isopiestic method is unlikely to yield as precise or accurate results as can be obtained using an apparatus of conventional design as described above, especially if the solutions are not stirred. In the tests of the prototype for the high-temperature isopiestic unit at Oak Ridge National Laboratory, Soldano et al. [50] found that when isopiestic samples of three aqueous electrolytes of about $m \sim 1 \mathrm{~mol} \cdot \mathrm{kg}^{-1}$ each were equilibrated with a large reservoir of $m \sim 0.5 \mathrm{~mol} \cdot \mathrm{kg}^{-1} \mathrm{NaCl}(\mathrm{aq})$ without stirring, it took about 3 days to reach isopiestic equilibrium at $T=378 \mathrm{~K}, 10$ days at $T=358 \mathrm{~K}$ and an estimated 60 days at $T=318 \mathrm{~K}$ where mixing of the solutions occurred solely by diffusion in the liquid state. Obviously, attempting to reach isopiestic equilibrium at lower temperatures such as $T=298.15 \mathrm{~K}$ will be impractical without stirring of the solutions.

All of the isopiestic studies described above involve solutions that are liquid in the temperature range of near the solvent freezing temperature to near the solution boiling temperatures. However, there is nothing inherent in the isopiestic method that limits its applications to these conditions, and measurements can be made for solutions that only become liquid at elevated temperatures. Zhi-Chang Wang (See Fig. 1) in an invited review article [51] has described his extensive work in extending the method to liquid solutions of metals in mercury at $T=600 \mathrm{~K}$, molten metal chloride mixtures at $T=873 \mathrm{~K}$, and metal oxides (slags) at $T=1273 \mathrm{~K}$. Obviously the design of isopiestic chambers and the choice of containers for holding the solutions at such elevated temperatures will be quite different than those being used for aqueous and alcohol solutions. The apparatus used by Wang was constructed from stainless steel with crucibles of spectral-grade graphite for the mercury solutions; for the molten chlorides and molten oxides the apparatus and crucibles were made from quartz with a thin coating of platinum added on the inner surface of the crucibles for the molten oxide experiments.

\section{Related Experimental Methods}

There are some other methods that can be used to measure the water vapor pressures (water activities) of aqueous solutions that possess some features common with the isopiestic method. One of these is the electrodynamic balance method that was described by Richardson and Spann [52]. In this method a microscopic particle of a solid electrolyte is electrically charged and suspended in an electrodynamic balance, yielding a measure of its dry mass. Water vapor is slowly admitted from an external source and the change in mass is determined as a function of the relative humidity after the sample deliquesces and become a liquid solution, and then the water is slowly removed until crystallization occurs. Since the liquid solution range of the suspended particle is controlled by homogeneous nucleation rather than by heterogeneous nucleation, considerable degrees of oversaturation can be achieved. Although not a very precise method, it can yield results at very high concentrations not accessible by other methods.

El Guendouzi and Dinane [53] described a different method for determining water activities that they named the hygrometric method. A thin thread is placed above the solution to be studied and a small droplet of reference solution, $\mathrm{NaCl}(\mathrm{aq})$ or $\mathrm{LiCl}(\mathrm{aq})$, is placed on the 


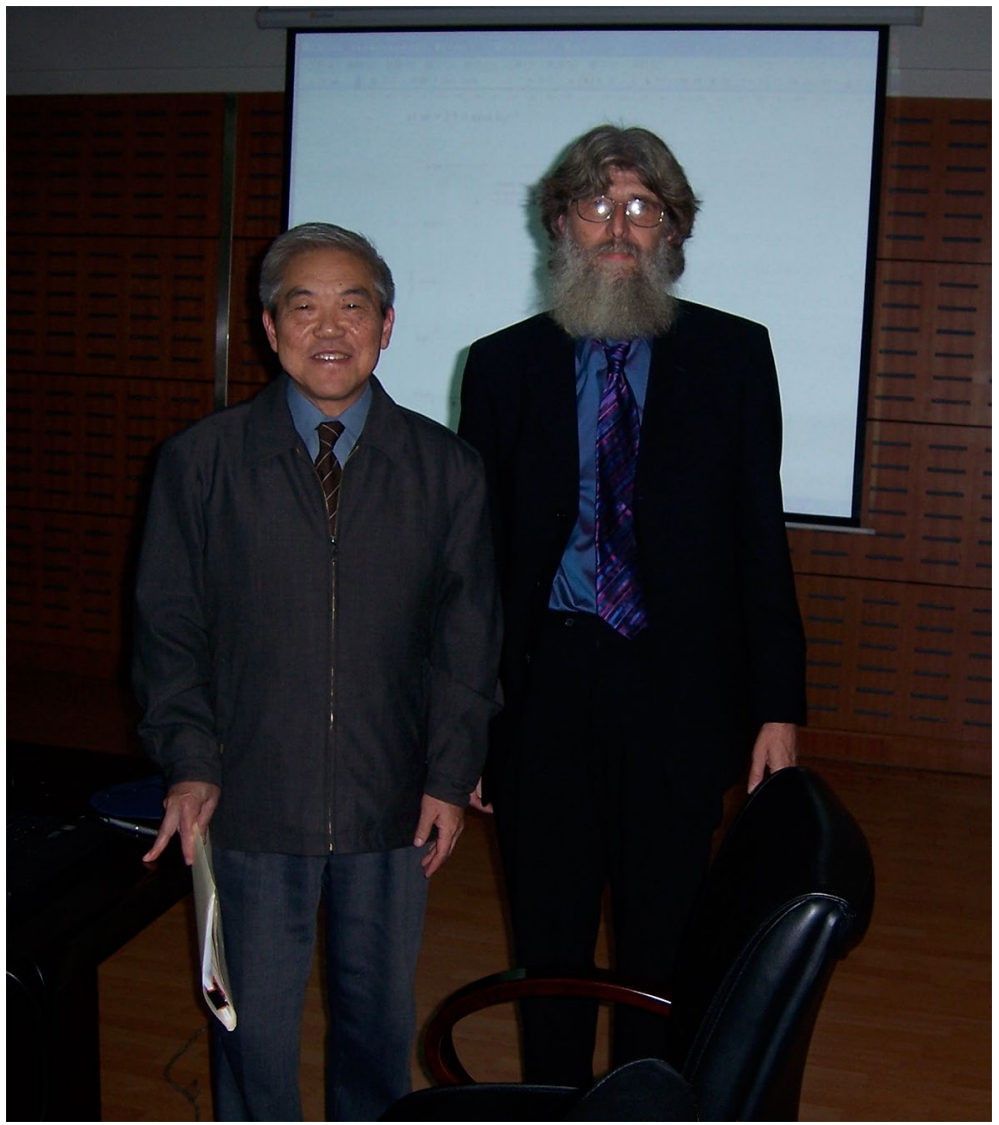

Fig. 1 Professor Zhi-Chi Wang (left) and the author, Joseph A. Rard. Photograph taken 16 October 2008 at Northeastern University, Shenyang, China, using the author's camera. Prof. Wang has applied the isopiestic equilibration method to studying a very diverse range of aqueous and non-aqueous systems including molten solutions of metal amalgams, metal chlorides and metal oxides

thread. As the concentration of the studied solution is changed the diameter of the reference solution droplet swells or shrinks depending on the amount of water vapor absorbed or lost. By measuring the radius of this droplet when in water vapor equilibrium with the investigated solution, its molality and thus its water activity can be estimated. Although not as precise as results from the mass measurements of the isopiestic method used for determining molalities of solutions at equilibrium, the hygrometric method does provide useful water activity data.

\section{Summary}

The isopiestic method was first developed to study hygroscopic properties of initially dry solids [1] but this application has been largely superseded by the determination of solvent activities and from them activity coefficients. However, as indicated by the reports of Tereshchenko [54,55], it is still being applied for studying hygroscopic properties and 
can even be used to detect the presence of significant levels of impurities in the solid salts being studied.

This review of the isopiestic method has attempted to cover the most important experimental aspects of this method and its major applications. The four experimental papers submitted to this special issue include two devoted to its traditional use to determine water activities and osmotic coefficients of aqueous electrolyte solutions [56, 57] and two papers investigating hygroscopic properties of solid salts $[54,55]$. There is also a review of its applications to systems that only become liquid at very high temperatures [51].

Acknowledgment The author is grateful to Professor Anatoly G. Tereshchenko for suggesting this special issue and Professors Glenn Hefter and Peter May for helpful suggestions.

\section{References}

1. Bousfield, W.R.: Iso-piestic solutions. Trans. Faraday Soc. 13, 401-413 (1918)

2. Sinclair, D.A.: A simple method for accurate determination of vapor pressures of solutions. J. Phys. Chem. 37, 495-504 (1933)

3. Robinson, R.A., Sinclair, D.A.: The activity coefficients of the alkali chlorides and lithium iodide in aqueous solution from vapor pressure measurements. J. Am. Chem. Soc. 56, 1830-1835 (1934)

4. Rard, J.A., Platford, R.F.: Experimental methods: isopiestic. In: Pitzer, K.S. (ed.) Activity Coefficients in Electrolyte Solutions, 2nd edn. CRC Press, Boca Raton (1991)

5. Scatchard, G., Hamer, W.J., Wood, S.E.: Isotonic solutions. I. The chemical potential of water in aqueous solutions of sodium chloride, potassium chloride, sulfuric acid, sucrose, urea and glycerol at $25^{\circ}$. J. Am. Chem. Soc. 60, 3061-3070 (1938)

6. Spedding, F.H., Weber, H.O., Saeger, V.W., Petheram, H.H., Rard, J.A., Habenschuss, A.: Isopiestic determination of the activity coefficients of some aqueous rare earth solutions at $25{ }^{\circ} \mathrm{C}$. 1 . The rare earth chlorides. J. Chem. Eng. Data 21, 341-360 (1976)

7. Rush, R.M., Johnson, J.S.: Osmotic coefficients of synthetic sea-water solutions at $25{ }^{\circ} \mathrm{C}$. J. Chem. Eng. Data 11, 590-592 (1966)

8. Rard, J.A., Clegg, S.L., Palmer, D.A.: Isopiestic determination of the osmotic coefficients of $\mathrm{Na}_{2} \mathrm{SO}_{4}$ (aq) at 25 and $50{ }^{\circ} \mathrm{C}$, and representation with ion-interaction (Pitzer) and mole fraction thermodynamic models. J. Solution Chem. 29, 1-49 (2000)

9. Robinson, R.A.: The activity coefficients of the alkali bromides and iodides in aqueous solution from vapor pressure measurements. J. Am. Chem. Soc. 57, 1161-1165 (1935)

10. Lindenbaum, S., Boyd, G.E.: Osmotic and activity coefficients for the symmetrical tetraalkyl ammonium halides in aqueous solution at $25^{\circ}$. J. Phys. Chem. 68, 911-917 (1964)

11. Popović, D.Ž., Miladinović, J., Miladinović, Z.P., Grujić, S.R., Todorović, M.D., Rard, J.A.: Isopiestic determination of the osmotic and activity coefficients of the $\left\{y \mathrm{KBr}+(1-y) \mathrm{K}_{2} \mathrm{HPO}_{4}\right\}(\mathrm{aq})$ system at $T=298.15$ K. Chem. Thermodyn. 62, 151-161 (2013)

12. Stokes, R.H.: A thermodynamic study of bivalent metal halides in aqueous solution. Part XIII. Properties of calcium chloride solutions up to high concentrations at $25^{\circ}$. Trans. Faraday Soc. 41, 637-641 (1945)

13. Libuś, Z., Sadowska, T., Trzaskowski, J.: Osmotic coefficients of aqueous rare-earth perchlorates and nitrates. J. Chem. Thermodyn. 11, 1151-1161 (1979)

14. Covington, A.K., Robinson, R.A., Thompson, R.: Osmotic and activity coefficients for aqueous methane sulfonic acid solutions at $25{ }^{\circ} \mathrm{C}$. J. Chem. Eng. Data 18, 422-423 (1973)

15. Robinson, R.A., Wilson, J.M., Stokes, R.H.: The activity coefficients of lithium, sodium and potassium sulfate and sodium thiosulfate at $25^{\circ}$ from isopiestic vapor pressure measurements. J. Am. Chem. Soc. 63, 1011-1013 (1941)

16. Miller, G., Porter, A.S.: Activity coefficients of some polyphosphates in aqueous solution. Trans. Faraday Soc. 63, 335-340 (1967)

17. Kirgintsev, A.N., Luk'yanov, A.V.: Isopiestic investigations of ternary solutions. VII. Ternary solutions lithium chloride-caesium chloride-water, potassium chloride-caesium chloride-water, rubidium chloride-caesium chloride-water, potassium chloride-calcium chloride-water, and potassium chloridemagnesium chloride-water. Russ. J. Phys. Chem. 40, 686-688 (1966) 
18. Holmes, H.F., Baes Jr., C.F., Mesmer, R.E.: Isopiestic studies of aqueous solutions at elevated temperatures. I. $\mathrm{KCl}, \mathrm{CaCl}_{2}$, and $\mathrm{MgCl}_{2}$. J. Chem. Thermodyn. 10, 983-996 (1978)

19. Rard, J.A., Weber, H.O., Spedding, F.H.: Isopiestic determination of the activity coefficients of some aqueous rare earth solutions at $25{ }^{\circ} \mathrm{C}$. 2. The rare earth perchlorates. J. Chem. Eng. Data 22, 187-201 (1977)

20. Rard, J.A.: Isopiestic determination of the osmotic coefficients of aqueous $\mathrm{H}_{2} \mathrm{SO}_{4}$ at $25{ }^{\circ} \mathrm{C}$. J. Chem. Eng. Data 28, 384-387 (1983)

21. Rard, J.A.: Isopiestic determination of the osmotic and activity coefficients of the $\left\{h \mathrm{H}_{2} \mathrm{SO}_{4}+(1-h)-\right.$ $\left.\mathrm{Al}_{2}\left(\mathrm{SO}_{4}\right)_{3}\right\}(\mathrm{aq})$ system at $T=298.15 \mathrm{~K}$. 1. Experimental results at stoichiometric ionic molality fractions $h=(0.85777,0.71534,0.57337,0.42985,0.28593$, and 0.14332). J. Solution Chem. 47, 1556-1577 (2018)

22. Gordon, A.R.: Isopiestic measurements in dilute solutions; the system potassium chloride-sodium chloride at $25^{\circ}$ at concentrations from 0.03 to 0.10 molal. J. Am. Chem. Soc. 65, 221-224 (1943)

23. Platford, R.F.: Thermodynamics of aqueous solutions of orthophosphoric acid from the freezing point to 298.15 K. J. Solution Chem. 4, 591-598 (1975)

24. Glueckauf, E., Kitt, G.P.: Thermodynamic data on concentrated sulphuric acid solutions. Trans. Faraday Soc. 52, 1074-1079 (1956)

25. Holmes, H.F., Baes Jr., C.F., Mesmer, R.E.: Isopiestic studies of aqueous solutions at elevated temperatures. II. $\mathrm{NaCl}+\mathrm{KCl}$ mixtures. J. Chem. Thermodyn. 11, 1035-1050 (1979)

26. Wexler, A., Greenspan, L.: Vapor pressure equation for water in the range 0 to $100{ }^{\circ} \mathrm{C}$. J. Res. Nat. Bur. Stand. 75A, 213-230 (1971)

27. Humphries, W.T., Kohrt, C.F., Patterson, C.S.: Osmotic properties of some aqueous electrolytes at $60{ }^{\circ} \mathrm{C}$. J. Chem. Eng. Data 13, 327-330 (1968)

28. Grjotheim, K., Voigt, W., Haugsdal, B., Dittrich, D.: Isopiestic determination of osmotic coefficients at $100{ }^{\circ} \mathrm{C}$ by means of a simple apparatus. Acta Chem. Scand. Ser. A 42, 470-476 (1988)

29. Hefter, G., May, P.M., Marshall, S.L., Cornish, J., Kron, I.: Improved apparatus and procedures for isopiestic studies at elevated temperatures. Rev. Sci. Instrum. 68, 2558-2567 (1997)

30. Kirgintsev, A.N., Luk'yanov, A.V.: Non-vacuum apparatus for determining vapor pressure by the isopiestic method. Russ. J. Phys. Chem. 37, 121-122 (1963)

31. Michimoto, T., Awakura, Y., Majima, H.: Isopiestic determination of the activity of water in aqueous sulfuric acid-sulfate systems. Denki Kagaku 51, 373-380 (1983)

32. Mitchell, J.P., Butler, J.B., Albright, J.G.: Measurement of mutual diffusion coefficients, densities, viscosities, and osmotic coefficients for the system $\mathrm{KSCN}-\mathrm{H}_{2} \mathrm{O}$ at $25{ }^{\circ} \mathrm{C}$. J. Solution Chem. 21, 1115-1129 (1992)

33. Rard, J.A.: Isopiestic determination of the osmotic and activity coefficients of $\left\{z \mathrm{H}_{2} \mathrm{SO}_{4}+(1-z)-\right.$ $\left.\mathrm{MgSO}_{4}\right\}(\mathrm{aq})$ at the temperature $T=298.15 \mathrm{~K}$. I. Results for $z=(0.85811,0.71539$, and 0.57353$)$. Chem. Thermodyn. 29, 533-555 (1990)

34. Holmes, H.F., Mesmer, R.E.: Isopiestic studies of $\mathrm{H}_{2} \mathrm{SO}_{4}(\mathrm{aq})$ at elevated temperatures thermodynamic properties. J. Chem. Thermodyn. 24, 317-328 (1992)

35. Albright, J.G., Rizzo, P., Rard, J.A.: Isopiestic determination of the osmotic and activity coefficients of $\mathrm{Cu}\left(\mathrm{NO}_{3}\right)_{2}(\mathrm{aq})$ at the temperature $298.15 \mathrm{~K}$. J. Chem. Thermodyn. 30, 327-352 (1998)

36. Rard, J.A.: Isopiestic investigation of water activities of aqueous $\mathrm{NiCl}_{2}$ and $\mathrm{CuCl}_{2}$ solutions and the thermodynamic solubility product of $\mathrm{NiCl}_{2} \cdot 6 \mathrm{H}_{2} \mathrm{O}$ at $298.15 \mathrm{~K}$. J. Chem. Eng. Data 37, 433-442 (1992)

37. Pitzer, K.S.: Ion-interaction approach: theory and data correlation. In: Pitzer, K.S. (ed.) Activity Coefficients in Electrolyte Solutions, 2nd edn. CRC Press, Boca Raton (1991)

38. Archer, D.G.: Thermodynamic properties of the $\mathrm{NaCl}+\mathrm{H}_{2} \mathrm{O}$ system. II. Thermodynamic properties of $\mathrm{NaCl}(\mathrm{aq}), \mathrm{NaCl} \cdot 2 \mathrm{H}_{2} \mathrm{O}(\mathrm{cr})$, and phase equilibria. J. Phys. Chem. Ref. Data 21, 793-829 (1992)

39. Archer, D.G.: Thermodynamic properties of the $\mathrm{KCl}+\mathrm{H}_{2} \mathrm{O}$ system. J. Phys. Chem. Ref. Data 28, 1-17 (1999)

40. Clegg, S.L., Rard, J.A., Pitzer, K.S.: Thermodynamic properties of $0-6 \mathrm{~mol} \mathrm{~kg}^{-1}$ aqueous sulfuric acid from 273.15 to 328.15 K. J. Chem. Soc. Faraday Trans. 90, 1875-1894 (1994)

41. Rard, J.A., Habenschuss, A., Spedding, F.H.: A review of the osmotic coefficients of aqueous $\mathrm{H}_{2} \mathrm{SO}_{4}$ at $25^{\circ} \mathrm{C}$. J. Chem. Eng. Data 21, 374-379 (1976)

42. Rard, J.A., Clegg, S.L.: Critical evaluation of the thermodynamic properties of aqueous calcium chloride. 1. Osmotic and activity coefficients of $0-10.77 \mathrm{~mol} \mathrm{~kg}^{-1}$ aqueous calcium chloride solutions at $298.15 \mathrm{~K}$ and correlation with extended Pitzer ion-interaction models. J. Chem. Eng. Data 42, 819-849 (1997)

43. Rard, J.A.: Solubility determinations by the isopiestic method and application to aqueous lanthanide nitrates at $25^{\circ} \mathrm{C}$. J. Solution Chem. 14, 457-471 (1985) 
44. Wang, Z.-C., Li, X.-Y., Liu, Y.-H.: Isopiestic studies on (methanol + sodium bromide + ammonium bromide) at the temperature $298.15 \mathrm{~K}$ : comparison with the partial ideal solution model. J. Chem. Thermodyn. 30, 709-712 (1998)

45. Wang, M., Wang, Z.-C.: Isopiestic studies on the quaternary system (water + ethanol+sodium bromide + ammonium bromide) at the temperature $298.15 \mathrm{~K}$ : comparison with the ideal-like solution model. J. Chem. Eng, Data 54, 517-519 (2009)

46. Zafarani-Moattar, M.T., Jahanbin-Sardroodi, J.: Isopiestic determination of osmotic coefficients and evaluation of vapor pressures for electrolyte solutions of some lithium salts in ethanol. Fluid Phase Equil. 166, 207-223 (1999)

47. Zafarani-Moattar, M.T., Jahanbin-Sardroodi, J.: Measurement and correlation of osmotic coefficients and evaluation of vapor pressures for solutions of $\mathrm{CaCl}_{2}$ and $\mathrm{Ca}\left(\mathrm{NO}_{3}\right)_{2}$ in ethanol at $298 \mathrm{~K}$. Fluid Phase Equil. 172, 221-235 (2000)

48. Zafarani-Moattar, M.T., Aria, M.: Isopiestic determination of osmotic and activity coefficients for solutions of $\mathrm{LiCl}, \mathrm{LiBr}$, and $\mathrm{LiNO}_{3}$ in 2-propanol at $25^{\circ} \mathrm{C}$. J. Solution Chem. 30, 351-363 (2001)

49. Ochs, L.R., Kabiri-badr, M., Cabezas Jr., H.: An improved isopiestic method to determinine activities in multicomponent mixtures. AIChE J. 36, 1908-1912 (1990)

50. Soldano, B.A., Stoughton, R.W., Fox, R.J., Scatchard, G.: A high-temperature isopiestic unit. In: Hamer, W.J. (ed.) The Structure of Electrolyte Solutions. Wiley, New York (1959)

51. Wang, Z.-C.: Isopiestic method for solution model verifications and binodal determinations. J. Solution Chem. 48, this special issue. https://doi.org/10.1007/s10953-018-0799-8

52. Richardson, C.B., Spann, J.F.: Measurement of the water cycle in a levitated ammonium sulfate particle. J. Aerosol Sci. 15, 563-571 (1984)

53. El Guendouzi, M., Dinane, A.: Determination of water activities, osmotic and activity coefficients in aqueous solutions using the hygrometric method. J. Chem. Thermodyn. 32, 297-310 (2000)

54. Tereshchenko, A.G.: Application of hygroscopic gravimetric analysis method in isopiestic measurements. Quality control of initial reagents. J. Solution Chem. 48, this special issue. https://doi. org/10.1007/s10953-018-0759-3

55. Tereshchenko, A.G.: Using the isopiestic method to study hygroscopic properties of soluble solutes. J. Solution Chem. 48, this special issue. https://doi.org/10.1007/s10953-018-0840-y

56. Ivanović, T., Popović, D.Ž., Miladinović, J., Rard, J.A., Miladinović, Z.P., Belošević, S., Trivunac, K.: Isopiestic determination of the osmotic and activity coefficients of the $\left\{y \mathrm{NaH}_{2} \mathrm{PO}_{4}+(1-y) \mathrm{KH}_{2} \mathrm{PO}_{4}\right\}-$ (aq) system at $T=298.15$ K. J. Solution Chem. 48, this special issue. https://doi.org/10.1007/s1095 3-018-0839-4

57. Li, H., Guo, L., Li, J.: Water activity and solubility of the system $\mathrm{MgCl}_{2}-\mathrm{RbCl}-\mathrm{H}_{2} \mathrm{O}$ at $323.15 \mathrm{~K}$. J. Solution Chem. 48, this special issue. https://doi.org/10.1007/s10953-018-0837-6

Publisher's Note Springer Nature remains neutral with regard to jurisdictional claims in published maps and institutional affiliations. 